\title{
Treatment Options in Myelodysplastic Syndromes
}

\author{
Klara Gadó and Gyula Domján \\ Semmelweis University, Faculty of Medicine, \\ $1^{\text {st }}$ Department of Internal Medicine
}

Hungary

\section{Introduction}

Myelodysplastic syndromes are a heterogeneous group of clonal bone marrow disorders, which are considered to be cancers and have a tendency to transform into acute myeloid leukemia. MDS are characterised by the underproduction of normal blood cells. Diseaseinduced cytopenias result infections and bleeding complications.

The diverse pathobiology of the disease is manifested by a varied clinical course, with some patients having more indolent disease and longer life expectancy, and others presenting with aggressive variants that rapidly progress to AML.

The frequency of the disease is the highest in the elderly. Number of diagnoses has increased in the past decade as a consequence of the increased recognition, and the aging of the population.

Prognosis is influenced by the age and co-morbidities of the patient and also by the cytogenetic abnormalities.

Risk stratification is based on the number of myeloblast in the bone marrow, the number of cytopenias and the cytogenetic abnormalities. The most widely used prognostic systems are the International Prognostic Scoring System (IPSS) and the WHO classification-based Prognostic Scoring System (WPSS). The latter system incorporates transfusion burden as well (Greenberg, 1998).

From the standpoint of both disease biology and prognosis, it is important to distinguish primary MDS from therapy-related MDS; the latter is closely related to therapy-related AML and develops in the setting of prior exposure to chemotherapy (eg, alkylating agents, topoisomerase II inhibitors), radiotherapy, radiation accidents, benzene, or other toxins and is prognostically worse than primary MDS. Response to therapy is highly worse in this group of patients (Tefferi, 2010; Graubert, 2010).

Treatment of MDS in the past was restricted to supplementation of the missing cell type thus relieving the patient's symptoms. Advances over the last decade have given a multitude of treatment options. Therapeutic options now exist that not only reduce diseaserelated symptoms, improve quality of life, but alter the natural history of the disease as well.

\section{Epidemiology}

The incidence of newly diagnosed MDS exceeds 10.000 cases in the US annually. MDS are the most common in older patients. At the time of diagnosis, $86 \%$ of patients are 60 years or 
older. The incidence of MDS rises from 3,4 cases per 100.000 in the general population to 15 to 50 cases per 100.000 in people older than 75 years (Giralt et al., 2011).

The incidence and prevalence of MDS has increased significantly over the past 20 years as a result of increasing longevity of the population and increasing physician awareness (Goldberg et al., 2010).

Among patients diagnosed with MDS, $14 \%$ have been treated for other primary tumors prior to diagnosis (Ma et al., 2007; Sekeres, 2011a).

\section{Survival}

Patient outcomes vary depending on disease presentation. Among untreated patients with MDS, median survival varies from 5,7 years in low-risk patients to 0,4 years in patients with high risk disease. For patients with $\operatorname{del}(5 \mathrm{q})$ as the only chromosomal aberration, medial survival is 73 months compared to 19,3 months for patients with more than one aberration. Transfusion need at diagnosis is the most independent parameter for survival, with transfusion-dependent patients having a median survival of 39 months versus 97 months for transfusion-independent patients.

\section{Staging system, risk stratification}

The IPSS was the first system to stratify patients according to their risk of death or evolution to AML. It is based on percentage of bone marrow blasts, cytogenetic abnormalities, and number of cytopenias. However, the IPSS does not consider the severity of anaemia and

\begin{tabular}{|c|c|c|c|c|c|c|}
\hline \multicolumn{7}{|c|}{ Factors for determining IPSS score } \\
\hline & \multicolumn{6}{|c|}{ Score value } \\
\hline $\begin{array}{c}\text { Prognostic } \\
\text { variable }\end{array}$ & 0 & \multicolumn{2}{|c|}{0.5} & 1.0 & 1.5 & 2.0 \\
\hline $\begin{array}{l}\text { Blasts in } \\
\text { marrow } \\
(\%)\end{array}$ & $<5$ & \multicolumn{2}{|c|}{$5-10$} & - & $11-20$ & $21-30$ \\
\hline Karyotype & good & \multicolumn{2}{|c|}{ Intermediate } & Poor & - & - \\
\hline Cytopenias & $0 / 1$ & \multicolumn{2}{|c|}{$2 / 3$} & - & - & - \\
\hline \multicolumn{7}{|c|}{$\begin{array}{l}\text { Good = normal, }-\mathrm{Y}, \operatorname{del}(5 \mathrm{q}), \operatorname{del}(20 \mathrm{q}) \\
\text { poor }=\text { complex }(3 \text { abnormalities }) \text { or chromosome } 7 \text { anomalies; } \\
\text { intermediate }=\text { other abnormalities. }\end{array}$} \\
\hline \multicolumn{7}{|c|}{ Risk of transformation and median survival } \\
\hline Risk & \multicolumn{2}{|c|}{ Total score } & \multicolumn{2}{|c|}{$\begin{array}{l}\text { Progression to AML } \\
\text { Without therapy } \\
\text { (year) }\end{array}$} & \multicolumn{2}{|c|}{$\begin{array}{c}\text { Median survival } \\
\text { Without therapy (years) }\end{array}$} \\
\hline Low & \multicolumn{2}{|c|}{0} & \multicolumn{2}{|c|}{9.4} & \multicolumn{2}{|c|}{5.7} \\
\hline Int-1 & \multicolumn{2}{|c|}{$0.5-1.0$} & \multicolumn{2}{|c|}{3.3} & \multicolumn{2}{|c|}{3.5} \\
\hline Int-2 & \multicolumn{2}{|c|}{$1.5-2.0$} & \multicolumn{2}{|c|}{1.1} & \multicolumn{2}{|c|}{1.2} \\
\hline High & \multicolumn{2}{|c|}{$\geq 2.5$} & \multicolumn{2}{|c|}{0.2} & \multicolumn{2}{|c|}{0.4} \\
\hline
\end{tabular}

Int-1 = intermediate-1, Int-2 = intermediate-2

Table 1. The International Prognostic Score System (IPSS) for MDS 
transfusion requirement, which are definitely associated with reduced survival in MDS. The newer WPSS has five prognostic groups with distinct survival times and probabilities of progression to AML. While the IPSS is limited to newly diagnosed patients with MDS, the WPSS can be applied at any time during the disease course. It has been shown that the WPSS improves survival prediction and identifies patients with very low-risk disease who may achieve long-term survival.

\begin{tabular}{|c|c|c|c|c|c|}
\hline Variable & $\mathbf{0}$ & $\mathbf{1}$ & $\mathbf{2}$ & $\mathbf{3}$ & \\
\hline $\begin{array}{c}\text { WHO } \\
\text { category }\end{array}$ & RA, RARS, 5q- & $\begin{array}{c}\text { RCMD, } \\
\text { RCMD-RS }\end{array}$ & RAEB-1 & RAEB-2 & \\
\hline Karyotype & Good & Intermediate & Poor & - & \\
\hline $\begin{array}{c}\text { Transfusion } \\
\text { requirement }\end{array}$ & No & Regular & - & - & \\
\hline
\end{tabular}

Abbreviations: RA = refractory anaemia; RAEB-1 = refractory anaemia with excess blasts type 1; RAEB2 = refractory anaemia with excess blasts type 2 ; RARS = refractory anaemia with ringed sideroblasts; $\mathrm{RCMD}=$ refractory cytopenia with multilineage dysplasia; RCMD-RS = refractory cytopenia with multilineage dyslasia and ringed sideroblasts;

Table 2. The WHO Classification-Based Prognostic Score System (WPSS) for MDS

\section{New prognostic factors}

Conventional metaphase cytogenetic analysis is limited by the sensitivity of the assay, and therefore new technologies are being applied in MDS to detect genomic alterations. One of these approaches has been the use of single-nucleotide polymorphism arrays (SNP-A). Using SNP-A, several candidate genes have been described recently, and include c-CBL (encodes an E3 ubiquitin ligase that inhibits tyrosine kinase signalling) (Sanada et al., 2008), ASXL1, and TET-2 (which are significant because they may have a role in the control of epigenetic alterations in MDS.) (Boultwood et al., 2010; Jankowska et al., 2009; Garcia-Manero, 2010).

\section{Treatment goals and options}

The goals of treatment for patients with MDS are to prolong overall survival, reduce transfusion burden, and improve their quality of life (Scott, 2008).

Treatment options for individual patients with MDS depend on the disease classification, prognostic stage and the age and health status of the patient.

For patients with lower risk disease (IPSS: low- or intermediate-1-risk) options include lenalidomide, erythropoietin-stimulating agents and immunosuppressive therapy, as well as hypomethylating agents (azacitidine and decitabine). For patients with del(5q) syndrome lenalidomide is the treatment of choice. For patients with higher risk (IPSS: intermediate-2-, or high-risk), intensive therapy with allogeneic stem cell transplantation (alloSCT) remains the only potentially curative treatment option (Sekeres, 2009; Mufti \& Chen, 2008).

For the majority of patients who are not candidates for alloSCT, treatment options include azacitidine or decitabine, clinical trials, or supportive care.

In addition, all patients receiving active therapy should receive continuous supportive care. 


\section{Considerations regarding to select the appropriate treatment options}

Treatment consideration must take into account many factors, including the pathologic diagnosis, the prognosis based on the IPSS or WPSS, the unique disease features in that particular patient, feasibility of performing a clinical trial, the appropriateness of a bone marrow transplantation, and the philosophy of the patient and the family concerning his or her care (Malcovati \& Nimer, 2008; Barzi \& Sekeres, 2010; Greenberg, 2010).

In addition, if the patient has a secondary MDS, tolerability of therapy is probably worse because of previous exposure to DNA-damaging agents.

Older age per se has a negative impact on survival of MDS patients, in particular of those with low-risk disease. However, age affects the survival of high-risk patients indirectly as well, by limiting their eligibility to intensive treatments. In addition, aging is associated with an increasingly high risk of developing co-morbidity.

Co-morbidities have a significant impact on the outcome of patients with MDS. Risk stratification should also have to include the assessment of co-morbidities of the MDS patients.

One of the most important areas of research is the identification of biomarkers of response to therapy (Garcia-Manero, 2010). A critical example is the discovery by List et al. of the relationship between the presence of a chromosome 5 alterations and response to lenalidomide (List et al., 2006), which resulted in the development of targeted approaches to these patients, as well as an entirely new field of research with the discovery of RPS14 as a critical gene in 5q31 (Ebert et al, 2008). Predictors of responsiveness to immunosuppressive therapy are younger age, HLA-DR15 type, the interval between first transfusion and starting of immunosuppressive treatment. (Sloand et al., 2008; Barrett et al., 2006).

\section{Patient selection}

The selection of an adequate treatment option has to be preceded by thorough consideration, that have to take account of several points of view. The proper patient selection is the key element of successful treatment.

There is a significant role of the patient's intent beyond the severity of the illness in the embracement of the most appropriate treatment option in case of a given patient. Patient has to be committed to the treatment as he or she takes the risk of the adverse effects of the treatment, and also he or she undertakes the inconveniences of a long-term treatment process.

\section{Treatment modalities in MDS}

Taking into account the above mentioned aspects, there are several possibilities to choose: observation, supportive care, iron chelation, erythropoiesis-stimulating agents (EPOs), immunosuppressive treatment, intensive chemotherapy, and also disease-altering options: hypomethylating agents, lenalidomide, alloSCT, as well as entrance in a clinical trial (Barzi \& Sekeres, 2010).

\subsection{Observation}

Many patients, especially those who are older and frail, benefit from a period of observation before any discussion about the need for therapy is made. Treatment should be reserved 
only if there are symptoms resulting from anaemia or other cytopenias or perhaps presymptomatic anaemia or severe thrombocytopenia.

\subsection{Supportive therapy}

Supportive care includes transfusion of red blood cells and platelets to minimize complication of cytopenias and to improve quality of life, as well as antibiotics to treat infections.

Patients with symptomatic anaemia should receive transfusion to relieve their symptoms. Platelet transfusion must be given in case of severe thrombocytopenia which cause bleeding.

\subsection{Erythropoiesis-stimulating agents}

Once an MDS patient become transfusion-dependent, erythropoietin-stimulating agents (ESAs) can be considered. These include epoietin (Eprex) and darbopoietin alfa (Aranesp). The clinical practice guideline of the American Society of Haematology suggests to use epoietin and darbepoietin in adults with lower risk MDS without chemotherapy. Erythropoiesis stimulating agents are used by more than 50\% of patients (Sekeres, 2011a,).

Recently ESAs are increasingly used to treat anaemia of lower risk MDS, even before RBC transfusion requirement. Early introduction of ESA in lower risk MDS, may help to better avoid the consequences of anaemia and also to delay the need for RBC transfusions, hypothetically by slowing the disease course (Park et al., 2010).

EPOs are recommended particularly for those with low serum EPO level. Serum erythropoietin (EPO) level $<500 \mathrm{mU} / \mathrm{ml}$ may respond to EPO if relatively high doses are administered. The EPO dose required is 40.000-60.000 units 1-3 times a week subcutaneously. Erythroid response occur within 6 to 8 weeks of treatment (HellströmLindberg E, 2003; Jädersten et al., 2008).

In a phase 3 prospective randomized trial the efficacy and long-term safety of EPO with or without granulocyte colony-stimulating factor plus supportive care was evaluated versus supportive care alone for the treatment of anaemic patients with lower-risk MDS (Greenberg et al., 2009). In comparison with supportive care alone, patients receiving EPO with or without granulocyte colony-stimulating factor plus supportive care had improved erythroid responses, similar survival, and incidence of acute myeloid leukemia transformation. Responding patients had significantly lower serum EPO levels (45\% vs 5\% responses for levels $<200 \mathrm{mU} / \mathrm{mL}$ vs $\geq 200 \mathrm{mU} / \mathrm{mL}$ ). (Rizzo et al., 2010).

\subsection{Iron chelation therapy}

Many MDS patients are dependent on red blood cell (RBC) transfusions for symptomatic management of refractory anaemia. Iron overload ensues when the iron acquired from transfused RBCs exceeds body storage capacity, thereby raising the risk for end organ damage (List, 2010).

The use of iron chelation in myelodysplastic syndrome (MDS) has generated much controversy recently (Steensma, 2009a). Transfusion dependency is associated with shortened overall survival and leukemia-free survival in MDS. The major question is whether this effect is mediated by transfusional iron overload itself or if need for red cell transfusion is simply a marker of disease severity (Malcovati et al., 2005).

Averting cardiac dysfunction in low-grade MDS patients who have sufficient longevity to experience deleterious cardiac effects of iron overload has been the major argument in favor 
of iron chelation. However, the role of iron chelation therapy in MDS remains controversial. Although there is significant evidence showing the adverse impact of transfusion dependency on survival in MDS, direct evidence linking tissue iron overload to poor survival or in particular to cardiac dysfunction is lacking.

Present evidence suggesting that the major benefit of iron chelation in MDS is not likely to come from reduction in cardiac and other end organ damage due to tissue iron overload, but from a potential favorable impact on 3 other outcomes namely: lowering infection risk, improving the outcome of allogeneic hematopoietic stem cell transplantation, and delaying leukemic transformation. These outcomes have particular relevance for patients with higher grades of MDS (Pullarkat, 2009).

Application of recent advances in the treatment of MDS can reduce or eliminate the need for transfusions, thus minimizing the risk of iron overload.

Iron chelation strategies include oral agents such as deferasirox (Exjade, Novartis), deferiprone (Ferriprox, Apotex Europe BV,) and parenteral administration of deferoxamine (Desferal, Novartis).

Considering the short survival of patients with MDS, the benefit of iron chelation is debatable. This procedure is advised for those who have received more than 25 units of packed red blood cells.

Unfortunately, iron chelation is expensive and, to date, has not shown a clear survival benefit in the MDS population.

\subsection{Hypomethylating agents}

MDS pathophysiology is complex, and still not completely understood. Structural alterations in DNA play a role in the pathogenesis of disease. Epigenetic changes in the form of modifications to the transcriptional capacity of the cell via processes, such as DNA methylation can also alter gene expression impacting disease biology. As such, hypermethylation of the promoters of certain tumor suppression genes is prevalent in MDS and secondary AML, and it is postulated that the DNA hypomethylation may result in the reactivation of silenced genes, restoring their cancer-suppressing functions, and inducing cellular differentiation providing a biologically rational therapeutic target for MDS.

Currently, both FDA- (U.S. Food and Drug Administration) approved hypomethylating agents (azacitidine and decitabine) have shown good clinical responses in patients with MDS. In the last two decades the use of epigenetic therapy has gained popularity, given its favorable side effect profile and its potential to improve survival.

\subsubsection{Azacitidine (5-azacytidine; Vidaza)}

Azacitidine (5-azacytidine; Vidaza; Pharmion Corporation) for injectable suspension received regular approval by the FDA for the treatment of all subtypes of MDS in 2004. It was the first agent that has been reported to prolong survival in MDS patients.

\subsubsection{Mechanism of action}

Azacitidine is a nucleosid analog that incorporates into RNA and requires the activity of ribonucleotide reductase to be incorporated to DNA. The incorporation of azacitidine into DNA leads to inhibition of DNA methyltransferase (DNMT) which has been known to hypermethylate cytosine residues at cytosine-guanine repeat sequences. By reducing the quantity of hypermethylated DNA produced, azacitidine can serve to limit the proliferation 
of malignant cells, while allowing an increased proportion of normal cells to differentiate. Although azacitidine falls into the category of hypomethylating agents, its mechanism of action is likely multifactorial (Yang et al, 2010).

\subsubsection{Identification patients for azacitidine treatment}

Azacitidine was approved by the US FDA on the basis of CALGB (Cancer and Leukemia Group B) 9221. This randomized trial compared azacitidine with best supportive care (BSC) targeting high-intermediate and high-risk disease and including low-intermediate risk patients with ongoing complications of cytopenias. The results demonstrated superiority of azacitidine over BSC in terms of quality of life, reduced transfusion needs, and delayed time to AML transformation or death for higher risk patients (Kurtin \& Demakos. 2010,).

It was the AZA-001 trial (the second randomized trial, which was conducted to define whether an endpoint not of response but overall survival (OS) could be met with hypomethylation therapy) which revealed that azacitidine significantly improved OS compared to that of the conventionally treated patients (either BSC, low-dose cytosinearabinoside, or intensive induction chemotherapy). There was no particular "winner" regarding the different subsets of patients treated. Response benefit was distributed fairly evenly across various subgroups of patients. This was true across younger and older patients, gender, performance status, FAB subtype, WPSS, IPSS score, cytogenetic risk category, and bone marrow blasts rate (Edlin et al., 2010).

The rate of complete response (CR) was rather low in the AZA-001 trials $(17 \%$ in the azacitidine arm). The low CR rate provides compelling data against oncology dogma that achievement of $C R$ is required for survival benefit. Indeed, a retrospective subset analysis examined the survival impact of azacitidine excluding patients who achieved CR. One-year survival rates were superior for azacitidine treatment versus conventional treatment $(68 \%$ vs $56 \%, P=0,015)$, thus achieving a CR is no longer a sufficient predictor for a therapy's ability to extend survival and alter course of MDS.

Critical to the success of azacitidine is the selection of appropriate patients. Higher risk MDS patients who are of reasonable performance status with adequate organ function are excellent candidates and also those lower risk patients who are transfusion dependent or have severe cytopenias.

\subsubsection{Side effects}

Adverse events are inevitably encountered. Haematological toxicities are common, particularly in the first one to two cycles. Infections have occured in $50 \%$ of azacitidinetreated patients in AZA-001 trial. $58 \%$ of patients experienced thrombocytopenia and/or neutropenia.

Common other adverse effects are gastrointestinal (vomiting, diarrhoea, anorexia), fevers, rigors, arthralgia, headache, and dizziness (San Miguel Amigo, 2011).

\subsubsection{Dosage and administration}

For azacitidine the most appropriate dosing schedule is $75 \mathrm{mg} / \mathrm{m}^{2}$ subcutaneously for 7 days, every 4 weeks. It is also an important issue to keep on treatment for at least at six cycles. In case of the absence of unacceptable toxicity or the evidence of disease progression, therapy should be continued for the maintenance of the response. 


\subsubsection{Azacitidine for maintenance of complete remission after chemotherapy}

A Phase II prospective study was performed to assess the feasibility and efficacy of maintenance azacitidine for older patients with high-risk MDS in CR after induction chemotherapy. Sixty patients were enrolled and treated by standard induction chemotherapy. Patients that reached CR started maintenance therapy with subcutaneous azacitidine, 5/28 days until relapse. Median overall survival was 20 months. A dose of 60 $\mathrm{mg} / \mathrm{m}(2)$ was well tolerated. Grade III-IV thrombocytopenia and neutropenia occurred after 9.5 and $30 \%$ of the cycles, respectively, while haemoglobin levels increased during treatment. azacitidine treatment is safe, feasible and may be of benefit in a subset of patients (Grövdal et al., 2010).

\subsubsection{Decitabine (dezocitidine, Dacogen, SuperGen, Inc., Dublin)}

Decitabine is another hypomethylating agent approved by the US FDA in 2006 for the treatment of de novo and secondary MDS (for intermediate-1-, intermediate-2-, and high-risk MDS patients). It has been studied predominantly in higher-risk MDS patients.

The FDA approval was based on the randomized phase III trial (EORTC 06011) versus BSC using the European administration schedule. Decitabine-treated patients had improved quality of life, and reduced transfusion needs. Although there was a delayed time to AML transformation or death, this trial failed to shown any survival benefit for decitabine arm. The relatively short duration of therapy administered was the main limitation of the study design which may negatively affected outcomes (Garcia et al., 2010,).

Concerning studies with hypomethylating agents the best available evidence and consensus is that patients benefiting from therapy should continue treatment until progression or unacceptable toxicity.

The toxicity profile of the two AZA nucleotides is similar.

While the haematological response rates to both hypomethylating agents are similar, the survival advantage demonstrated by the FDA-approved dose schedule of azacitidine compared with conventional care, as well as the absence of such a survival advantage in response to the FDA-approved dose schedule of decitabine in two randomized studies, makes azacitidine the drug of choice for AZA nucleoside-naive, high-risk MDS patients. Perhaps the better-tolerated North American decitabine schedule would lead to similar survival advantage.

A comparative trial of azacitidine versus decitabine recently opened to accrual (http:// www.ClinicalTrials.gov; identifier: CT01011283). Unfortunately, the trial is designed with a primary endpoint of early response at 6 months and is not powered to examine the more relevant question of OS. (Blum, 2010)

\subsubsection{Dosage and administration of decitabine}

European schedule is $15 \mathrm{mg} / \mathrm{m}^{2}$ intravenously over 3 hours, every 8 hours for 3 days, repeated every 6 weeks Kantarjian et al., 2006). In North America, the typical schedule is 20 $\mathrm{mg} / \mathrm{m}^{2}$ intravenously over 1 hour daily for 5 days, repeated every 4 weeks, based on promising high CR results of up to $39 \%$ in a single center (Kantarjian et al., 2007). A multicenter study of 99 patients with MDS using the same regimen, The Alternative Dosing for Outpatient Treatment (ADOPT) trial, showed a CR rate of $17 \%$, with an overall response rate of $51 \%$ (Steensma et al., 2009b). The main point of administration is the number of cycles. The better OS results of azacitidine may be the consequence of the higher number of 
cycles. In the EORTC 06011 study the median number of cycles per patient was four, and $40 \%$ received two or fewer cycles. By comparison, the median number of cycles of AZA given in AZA-001 was nine.

\subsection{Lenalidomide}

Lenalidomide is an immunomodulatory drug that is FDA approved for lower risk patients with transfusion-dependent anaemia and an interstitial deletion of the long arm of chromosome $5[\operatorname{del}(5 q)]$. The approval was based on high rates of prolonged transfusion independence and complete cytogenetic response (Ximeri et al., 2010).

Treatment with a $10 \mathrm{mg}$ daily dose for 21 days in every 4 weeks results transfusion independence in $67 \%$ of patients with del(5q). Lenalidomide treatment does not increase risk of AML progression according to the preliminary result of MDS-004 study. It was a significant concern in Europe, preventing approval of the drug. Despite the frequent need of dose reduction due to myelosuppression, the starting dose of lenalidomide is suggested to be $10 \mathrm{mg}$ (Sekeres et al., 2008).

Though lenalidomide is approved by FDA for del(5q) lower risk subset of MDS patients, it is reasonable to consider lenalidomide as frontline treatment in the few higher risk patients with MDS who have both isolated $\operatorname{del}(5 q)$ and platelet count $>100.000 / \mu \mathrm{L}$ (Kurtin \& Demakos, 2010).

In case of patients with lower risk and without $\operatorname{del}(5 q)$ the ratio of patients reached transfusion independence was much lower and response duration was much shorter than that of patients with del $(5 q)$. Cytogenetic improvement was also inferior to that observed in the del(5q) patients. (Komrokji \& List, 2010;, List et al., 2006).

\subsubsection{Mechanism of action}

The drug may have different mechanism of activity, depending on the disease type.

In $\operatorname{del}(5 q)$, lenalidomide suppresses the malignant clone, but in non-del(5q) it appears to promote erythropoiesis.

There is now a better understanding of the mechanism of the karyotype-dependent drug action. In $\operatorname{del}(5 q)$ patients, lenalidomide suppresses the clone by inhibiting the nuclear sequestration of the haplodeficient cell cycle regulatory protein cdc25c, thereby promoting selective G2 arrest and apoptosis (Wei et al., 2009). In non-del(5q) patients, lenalidomide enhances erythropoietin receptor signaling.

\subsubsection{Combination treatment}

The addition of lenalidomide to azacitidine may provide additional clinical benefit over e monotherapy.

A recent Phase I trial testing the lenalidomide and azacitidine combination yielded encouraging results. In this study, 18 higher-risk MDS patients were treated with the combination for seven cycles, after which lenalidomide was discontinued in eight patients who achieved a complete response, with azacitidine monotherapy continuing until disease progression. Three patients who relapsed on monotherapy with excess blasts at 12, 19, and 24 months, in whom lenalidomide was then resumed in combination with azacitidine. Each patient, one with normal cytogenetics at relapse; one with a 18 abnormality; and one with del(4q25), recaptured a complete response that was sustained for 5, 7, and 7+ months.

The addition of lenalidomide to azacitidine provides additional clinical benefit over azacitidine monotherapy. (Sekeres et al., 2011b) 


\subsection{Immunosuppressive treatment}

An activated immune system has been observed in patients with myelodysplastic syndrome but its exact contribution to disease development and control is not fully clarified. On the one hand an activated and skewed T-cell repertoire has been reported, but on the other hand, decreased natural killer cell function has been found. Immune activation could reflect undesired autoimmune reactions against normal hematopoietic precursor cells as well as effective immune-surveillance against dysplastic clones (Chamuleau et al., 2009).

Autoreactive T-cell clones have a role in the apoptosis in the bone marrow of MDS, mainly in patients with hypocellular bone marrow. Immunosuppressive agents such as cyclosporine A (CsA)and anti-thymocyte globulin (ATG), or combination of the two agents can improve cytopenia and can reduce transfusion need in a subset of MDS patients. The anti-TNF agent etanercept can also be applied in combination with ATG. (Deeg et al., 2004).

Responses to immunosuppressive therapy in MDS remain among the most durable (and perplexing) of all available therapies in the disease. Typically, equine ATG is given at 40 $\mathrm{mg} / \mathrm{kg}$ intravenously for four consecutive days, in conjunction with methylprednisone and CsA. Initial reports of its use demonstrated achievement of transfusion independence in 21 of $61(34 \%)$ of patients. More importantly, the probability of continued transfusion independence after 5 years was $76 \%$. However, the toxicity of the regimen has led to considerable apprehension in its use.

Most ATG studies in MDS have been single center experiences, and several reports in unselected patients have demonstrated lower response rates and significant toxicity with the regimen. Clearly, judicious patient selection for the therapy is critical for its success and productive implementation. Helpful guidance for the use of ATG in MDS was recently published. Outcomes for patients with MDS who were given equine ATG (with or without CsA) in sequential protocols at the National Heart, Lung, and Blood Institute between 1971 and 2003 were described. For 129 ATG-treated patients, 39 patients (30\%) responded; 9\% had CR. Serious infusion-related toxicities were infrequent, but meaningful because $9 \%$ of patients required temporary intensive care unit support. Responses included 18 of $74(24 \%)$ treated with ATG alone, 20 of 42 (48\%) treated with ATG_CsA, and 1 of 13 (8\%) treated with CsA. Median response duration was 3 years ( 3 months to 10 years), and median survival in the cohort was 10,5 years. Notably, factors affecting response were younger age $(<60)$, HLADR15 positivity, and use of combination ATG+CsA. There was no association of response with pretreatment marrow cellularity, paroxysmal nocturnal hemoglobinuria clone, or absolute neutrophil count. Furthermore, a multivariate analysis of the IST-treated group compared with results from a control group of 816 patients with MDS from the International Myelodysplasia Risk Analysis Workshop database showed that survival was improved in younger patients, those treated with IST, and those with low/intermediate IPSS risk scores.

The role of IST in MDS treatment remains enigmatic, and the serious toxicities that can be encountered with its infusion and long-term immunosuppressive effects have properly led to hesitation to its use in community and academic practice. However, in a manner similar to the rigorous selection of patients for transplantation, appropriate selection of patients for IST affords some the opportunity for prolonged responses without the requirement for repeated maintenance chemotherapy (such as AZA or decitabine). IST should be considered instead of a hypomethylating agent for previously untreated, younger patients with MDS with low or Int-1 risk disease with HLADR15. 
Predictors of responsiveness are younger age, HLA-DR15 type, the interval between first transfusion and starting of immunosuppressive treatment. (Sloand et al., 2008; Barrett et al., 2006).

Passweg et al. reported open-label randomized phase III trial on patients with MDS randomly assigned to $15 \mathrm{mg} / \mathrm{kg}$ of horse ATG for 5 days and oral CSA for 180 days (ATG+CSA) (45 patients) or best supportive care (43 patients), stratified by treatment center and International Prognostic Scoring System (IPSS) risk score. Primary end point was best hematologic response at 6 months. This trial demonstrated that ATG+CSA treatment seems to be associated with hematologic response in a subset of patients without apparent impact on transformation free survival and OS (Passweg et al., 2011).

Because of the toxicities associated with ATG/CsA, an alternative regimen with alemtuzumab in MDS was investigated (Sloand et al., 2010). It was a nonrandomized, offlabel, pilot, phase I/II study of alemtuzumab monotherapy in patients with MDS who were judged likely to respond to immunosuppressive treatment based on the following criteria: HLA-DR15-negative patients whose age plus the number of months of RBC transfusion dependence (RCTD) was less than 58; and HLA-DR15-positive patients whose age plus RCTD was less than 72. Thirty-two patients were enrolled they received alemtuzumab 10 $\mathrm{mg} / \mathrm{d}$ intravenously for 10 days. Primary end points were hematologic responses at 3, 6, and 12 months after alemtuzumab. Seventeen (77\%) of 22 evaluable intermediate- 1 patients and four $(57 \%)$ of seven evaluable intermediate- 2 patients responded to treatment with a median time to response of 3 months. Four of seven evaluable responders with cytogenetic abnormalities before treatment had normal cytogenetics by 1 year after treatment. Five (56\%) of nine responding patients evaluable at 12 months had normal blood counts, and seven $(78 \%)$ of nine patients were transfusion independent. Alemtuzumab seems to be safe and active in MDS and may be an attractive alternative to ATG in selected patients likely to respond to IST.

\subsection{Intensive chemotherapy}

About $25 \%$ of patients with newly diagnosed MDS and 15-20\% of patients with established MDS have higher risk disease. These patients should be treated immediately, given the high likelihood of transformation to AML or death within 1.5 years. One of the treatment options is intensive chemotherapy (Bello et al., 2010; Gergis \& Wissa, 2010).

Intensive chemotherapy means some kind of acute leukemia protocol. One of them is the FLAG-Ida regimen. The combination of fludarabine, high dose cytarabine and granulocyte colony stimulating factor (FLAG) with idarubicin. According to a single centre experience treated a total of 105 patients over a 4 -year period with $59 \%$ achieving a complete remission. For patients responding to FLAG - Ida, the median event-free survival was 11 months at 5 years. Such patients proceeded either to further chemotherapy or a haematopoietic stem cell transplant (HSCT). The median EFS (13 months vs. 8 months) and projected 5-year survival (37\% vs. $13 \%$ ) of patients undergoing HSCT was significantly better than those who did not. The regimens were well tolerated, with the majority of patients experiencing grade 1 or less non-haematological toxicity (mainly nausea and vomiting). The median time to neutrophil and platelet recovery was 28 and 31 day, respectively. There was a $17 \%$ incidence of treatment-related deaths, of which $39 \%$ was caused by invasive aspergillus infection (Virchis et al., 2004). 
To date, no prospective randomized study has evaluated hypomethylating agents against intensive chemotherapy. Proponents of hypomethylating agents argue that they have a lower toxicity profile, allowing patients to receive therapy on an outpatient basis, and that the lower complete response rates do not necessarily translate into lower survival rates. This may be particularly relevant for older MDS patients, who are at higher risk of morbidity from intensive chemotherapy. (Scott \& Estey, 2008).

\subsection{Autologous stem cell transplantation}

Intensive chemotherapy with AML-like schedules followed by autologous stem cell transplantation may provide an alternative option for patients lacking a suitable donor. Intensive chemotherapy results in complete remission rates of 15-65\%. The median remission duration without stem cell transplantation is usually short due to a high incidence of early relapses. In view of the high relapse rate after chemotherapy alone transplantation with autologous stem cells after remission induction and consolidation chemotherapy has been applied in various clinical studies.

Autologous SCT has been extremely investigated in MDS. It is limited to patients who have achieved a CR, can be harvested, and are candidates for the procedure. Autologous SCT after successful induction chemotherapy may increase the proportion of long-term survivors, thus improving CR duration in some patients with MDS, particularly in younger patients in remission. Results for older patients are unsatisfactory. The relapse rate is up to $75 \%$, with a 2-year probability of disease-free survival of only $25 \%$ for patients $40-60$ years of age (Meletis \& Terpos, 2009).

Autologous peripheral stem cells (PB) result in faster hematopoietic recovery, but may be associated with a higher risk of relapse than bone marrow stem cells. In a study comparing 336 patients transplanted with either bone marrow $(B M)(n=104)$ or PB $(n=232)$. In the multivariate Cox model, the event-free survival was not different after PB or BM HSCT. The relapse risk after transplantation with stem cells from either source was similar. A significant interaction between age and the source of stem cells indicated a more favorable potential of autologous PB HSCT in young age groups. As autologous PB and BM HSCT result in equivalent outcomes, given the more rapid hematopoietic recovery $\mathrm{PB}$ is the preferred source of stem cells (de Witte et al., 2006).

According to the final results of a prospective randomized European Intergroup Trial (EORTC-06961) autologous stem cell transplantation does not provide longer survival than intensive chemotherapy (de Witte et al., 2010). Therefore, there is very limited enthusiasm for the future of autologous SCT in the management of MDS patients.

Patients with therapy-related MDS/AML had a significantly better disease-free survival than did those with the other categories of disease, even after adjustment for confounding factors in the Cox model, including interval between diagnosis and transplantation. The explanation of this unexpected outcome is not straightforward, but the contribution of patients with favorable cytogenetic characteristics might be relevant. We identified eight patients with $t(8 ; 21)$ or inversion 16 in an incomplete and ongoing analysis. The 3-year disease-free survival of these patients was $57 \%$ (de Witte et al., 2007).

\subsection{Allogeneic stem cell transplantation}

Despite the approval of three novel agents for MDS, allogeneic stem cell transplantation (alloSCT) is the only curative treatment modality for MDS patients. Allogeneic SCT replaces 
recipient dysplastic hemopoiesis with healthy donor haemopoiesis and immune system with an attendant graft-versus-leukemia (GvL) effect. Its applicability, however, is limited by the age of MDS patients, high rates of transplant-related mortality (TRM) and availability of a suitable HLA-matched donor. MDS is currently the third most common indication for alloSCT. As the disease is most frequent in the older population, the oftener use and acceptance of reduced-intensity conditioning (RIC) made the procedure more increased.

There are several unresolved issues in connection with transplantation. These are the impact of pre-transplant tumor debulking, the optimal timing and the transplantation of older patients and of those with co-morbidities, and also the issue of post-transplant maintaining therapy. The main difficulty is whether can we identify a subset of patients that could benefit from early transplantation and also a subset that are anticipated not going to benefit from alloSCT. Recent efforts to optimize the curative potential of transplant have focused on pretransplant therapy options, the use of predictive models to improve patient selection, and transplant modifications using reduced conditioning intensity.

Dependent upon disease status at the time of transplantation, $30 \%$ to $70 \%$ of patients can be expected to be cured of their disease and survive long term. However, posttransplant relapse and graft-versus-host disease (GvHD) remain problems (Bartenstein \& Deeg, 2010). No prospective randomized controlled trials have directly compared non-transplant therapies with SCT for MDS.

As more than $50 \%$ of the patients will fail to benefit from this treatment approach either due to TRM or to relapse after transplantation being mindful of patient selection is a main issue in decision making.

\subsubsection{Patient selection and decision making}

However, as the majority of patients with MDS are in the seventh or eighth decade of life careful consideration must be made to determine whether the patient is a candidate for alloSCT. Only approximately 5-10\% of higher risk MDS patients are alloSCT candidates.

Features to consider for alloSCT include the patient's age and IPSS score (moreover WPSS), performance status, co-morbid conditions, availability of a suitable donor (Warlick, 2010; Malcovati et al., 2005; Cutler, 2010a, 2010b;).

The proper assessment of co-morbidities becomes more important. A useful tool is hematopoietic cell transplantation co-morbidity index (HCTCI) developed by Sorror et a. (Sorror et al., 2005). It has been shown to have a predictive utility on survival also in MDS, even in case of patients getting only best supportive care (Zipperer et al., 2009). According to a study on 172 MDS patients assessing the impact of co-morbidities on survival and the prognostic utility of co-morbidity scores patients with an HCTCI of 0 had a median survival time of 68 months, those with an HCTCI of 1 or 2 lived for 34 months, and those with an HCTCI of $\geq 3$ survived for 25 months. The HCTCI was able to further subdivide the IPSS intermediate- 2 and high-risk groups. For patients in the IPSS intermediate-1 and low-risk groups, the HCTCI provided no additional prognostic information. The presence of pulmonary disease, gastrointestinal tract ulcers, cardiac disorders, and infection were independent prognostic factors for survival. HCTCI yielded prognostic information independent of the IPSS (Zipperer et al., 2009).

It is also important to determine whether the patient's marrow blast count is sufficiently low. Data suggest that patients with 5-20\% marrow blasts have only 25-28\% 5-year overall 
survival whereas lower risk patients (based on WPSS risk score) do well with alloSCT, with a 5 -year overall survival of $80 \%$ (Alessandrino et al., 2008).

\begin{tabular}{|c|c|c|c|c|c|}
\hline Risk groups & Patients & $\begin{array}{c}\text { NRM } \\
(\%)\end{array}$ & $\begin{array}{c}\text { Relapse } \\
(\%)\end{array}$ & $\begin{array}{l}\text { OS } \\
(\%)\end{array}$ & $\begin{array}{c}\text { RFS } \\
(\%)\end{array}$ \\
\hline \multirow{2}{*}{$\begin{array}{l}\text { Group I (HCT-CI scores 0-2 and low- } \\
\text { risk diseases) }\end{array}$} & $\begin{array}{l}\text { Myeloablative } \\
(\mathrm{n}=138)\end{array}$ & 11 & 14 & 78 & 75 \\
\hline & $\begin{array}{l}\text { Nonmyeloablative } \\
(\mathrm{n}=28)\end{array}$ & 4 & 33 & 70 & 63 \\
\hline \multirow{2}{*}{$\begin{array}{l}\text { Group II (HCT-CI scores 0-2 and } \\
\text { intermediate and high-risk diseases) }\end{array}$} & $\begin{array}{l}\text { Myeloablative } \\
(\mathrm{n}=176)\end{array}$ & 24 & 34 & 51 & 43 \\
\hline & $\begin{array}{l}\text { Nonmyeloablative } \\
(\mathrm{n}=34)\end{array}$ & 3 & 42 & 57 & 56 \\
\hline \multirow{2}{*}{$\begin{array}{l}\text { Group III (HCT-CI scores } \geq 3 \text { and } \\
\text { low-risk diseases) }\end{array}$} & Myeloablative $(n=52)$ & 32 & 27 & 45 & 41 \\
\hline & $\begin{array}{l}\text { Nonmyeloablative } \\
(\mathrm{n}=19)\end{array}$ & 27 & 37 & 41 & 36 \\
\hline \multirow{2}{*}{$\begin{array}{l}\text { Group IV (HCT-CI scores } \geq 3 \text { and } \\
\text { intermediate and high-risk diseases) }\end{array}$} & Myeloablative $(n=86)$ & 46 & 34 & 24 & 20 \\
\hline & $\begin{array}{l}\text { Nonmyeloablative } \\
\qquad(\mathrm{n}=44)\end{array}$ & 29 & 49 & 29 & 23 \\
\hline
\end{tabular}

Table 3. Two-year NRM, relapse, OS, and RFS incidences among 4 risk groups of nonmyeloablative and myeloablative patients with AML or MDS. Donors were either related $(n=301)$ or unrelated $(n=276)$ (Sorror et al., 2005).

\subsubsection{Appropriate timing of alloSCT}

The timing of transplantation has always been the most controversial topic of discussion for both patients and physicians. The lack of prospective data adds to the doubtfulness in this topic. Faced with the uncertainty of transplantation outcomes but the certainty of eventual MDS disease progression, decisions are often made based on patient preference. It is clear that there is inherent bias in these types of analyses, because the patients included are often selected and represent the best transplant candidates.

To address the shortcomings of these and other biased retrospective analyses, a Markov decision model was generated to best understand how treatment decisions would affect overall outcome in large cohorts of patients with newly diagnosed MDS (Cutler et al., 2004). The decision model was designed to determine if transplantation at the time of initial diagnosis, delayed a fixed number of years, or at the time of leukemic transformation was the optimal usage strategy for transplantation. Using data from several large, nonoverlapping databases, it was demonstrated that the optimal treatment strategy for patients with low- and intermediate-1-risk IPSS disease categories was to delay transplantation until the time of leukemic progression. Immediate transplantation was recommended for patients with high- and intermediate-2-risk IPSS scores (Cutler et al., 2004). However, a major limitation of this study is that it excluded patients over the age of 60 and focused solely on myeloablative conditioning. 
According to the retrospective registry study of de Witte et al. low risk patients benefited by early transplantation (within one year after diagnosis) versus more than 12 months from diagnosis. Estimated four-year overall survival was $57 \%$ versus $47 \%$ (de Witte et al., 2010). Beside the IPSS there are also important clinical events such as a new transfusion requirement, recurrent infection, or recurrent bleeding episodes that could be considered triggers to move on to transplantation. Transfusion requirement is a very strong predictor of the advantage of early transplantation. WPSS incorporates transfusion dependence into the score, and enables a dynamic assessment of prognosis during the time-course of the disease. WPSS appears more useful than IPSS particularly with respect to patients with low-risk disease (Malcovati et al., 2007). Presumably, identification of newer prognostic markers, using cytogenetic, immunophenotypic, and molecular techniques will enable further improvement in terms of risk stratification and help to clarify the optimal timing for transplantation, particularly for patients with low-risk disease.

\subsubsection{Conditioning regimen}

Standard myeloablative conditioning (SMC) results in high treatment-related mortality. While a high proportion of patients can achieve long-term disease control when undergoing transplantation in early phases of the disease using SMC, transplantation-related deaths account for $20 \%$ to $30 \%$ of treatment failures with such type of conditioning regimens (Bearman et al., 1988; de Lima et al., 2004).

A combination of busulfan (Bu) and cyclophosphamide (Cy) has been used as a standard myeloablative regimen for alloSCT. Recent studies postulate that fludarabine (Flu) is a less toxic substitute for Cy. Lee et al. compared the two regimens (BuCy vs BuFlu) and showed that there was no significant intergroup difference in the time of engraftment, nausea/vomiting, acute/chronic graft-versus-host disease, hepatic veno-occlusive disease, or hemorrhagic cystitis. Moreover, the 2 groups showed no significant difference in the cumulative risk of relapse, event-free survival, or overall survival (Lee et al., 2010; KindwallKeller \& Isola, 2009).

As the vast majority of MDS patients are over 60, using SMC is rarely an option. Conditioning regimens with less toxicity for alloSCT are being developed and should be available for a higher proportion of patients, particularly those who are elderly.

It has been well established that for many malignancies the curative potential of allogeneic transplantation is, in large part, due to the graft versus malignancy (GVM) effect. This has led to the development of less toxic, nonmyeloablative, and reduced intensity transplantation regimens that would provide donor cell engraftment and generation of a GVM effect. This approach has allowed treatment of older and debilitated patients who have been considered ineligible for transplantation using myeloablative regimens (de Lima et al., 2004; Gale \& Champlin, 1984).

Reduced-intensity conditioning regimens (these regimens cannot be safely administered without stem cell support) usually involve a combination of a purine analog (primarily fludarabine) with an alkylating agent (usually melphalan or busulfan). These reducedintensity regimens are generally considered to include less than $16 \mathrm{mg} / \mathrm{kg}$ busulfan or less than 10 Gy total body irradiation (Giralt et al., 1999, 2001). They have been usually associated with prompt engraftment of donor cells procured from both HLA-matched related and unrelated donors, while the truly nonablative regimens (NMA; can be given 
routinely without stem cell support, with neutrophil recovery within 28 days) have been associated with a varying degree of mixed chimerism and a higher risk of primary and secondary graft failures (de Lima et al., 2004).

However, there are currently no completed prospective randomized controlled studies comparing outcomes of RIC to myeloablating conditioning. The best insight into differences in outcome comes from large registry-based retrospective studies. These studies demonstrate that the use of RIC is associated with a reduction in transplant-related mortality but an increased risk of disease relapse. (Horwitz, 2011).

Based on recent relevant data regarding RIC for transplantation (Laport et al., 2008; McClune et al., 2010), patient age and disease status generally dictate the type of conditioning to be utilized. For example, those relatively older patients (i.e. $>50$ or 60 years) with $<10 \%$ marrow blasts would generally be recommended to receive RIC, whereas younger patients with a higher marrow blast burden would generally be recommended to receive standard conditioning. Regimens assessing novel approaches to RIC for MDS are being evaluated (Pagel et al, 2009).

At MD Anderson Cancer Center a retrospective analysis of transplantation outcomes was performed to determine whether in AML and MDS a reduced-intensity conditioning regimen would result in lower relapse rates than a truly nonablative regimen. Patients were included in this study if they had either AML or high-risk MDS and had undergone an alloSCT from an HLA-compatible donor with either a truly nonablative regimen of fludarabine, cytarabine (araC), and idarubicin (FAI) or with a RIC regimen with fludarabine in combination with melphalan 140 or $180 \mathrm{mg} / \mathrm{m}^{2}$ (FM140 or FM180). FAI was intended to be the treatment of choice for older patients ( $>55$ years) with early disease, having sibling donors and who were in remission, and with a high risk of relapse. The 2 doses of melphalan were investigated in an attempt to minimize toxicities observed with FM180. The lower age limit for participation in the FM studies was 55 years, but younger patients with organ dysfunction that made them ineligible for high-dose treatment protocols were also eligible. Both related and unrelated donors were allowed. Patients with more advanced disease were preferably treated with FM in order to provide higher dose intensity in the preparative regimen. The 3-year cumulative incidence of non-relapse-related mortality was significantly higher after conditioning with FM than with FAI. Conversely, the 3-year cumulative incidence of relapse-related mortality was higher after FAI than after FM. The analysis suggests that disease recurrence is more frequent in patients receiving the truly nonablative regimen as compared with those receiving the reduced-intensity regimen of fludarabine and melphalan. for AML and MDS both cytoreduction of the preparative regimen as well as GVM contribute to disease control after allografting with reducedintensity or nonablative conditioning regimens. The relative importance of these mechanisms, however, may differ with regimens other than those tested here. Truly nonablative regimens may be effective in minimal disease states or for diseases highly sensitive to GVM effects and may provide a platform for innovative cell therapy approaches that may obviate the need for direct cytoreduction of the malignancy (de Lima et al., 2004; Virchis et al., 2004).

There are studies intented to compare outcomes with different conditioning approaches. The relative efficacy of 3731 SMC transplant were compared with 1448 RIC/NMA procedures performed at 217 centers between 1997 and 2004 on AML/MDS patients. NMA 
conditioning resulted in inferior disease-free survival (DFS) and OS, but there was no difference in DFS and OS between RIC and SMC regimens. Late TRM negates early decreases in toxicity with RIC and NMA regimens. These data suggest that higher regimen intensity may contribute to optimal survival in patients with AML/MDS, suggesting roles for both regimen intensity and graft vs leukemia in these diseases (Luger et al., 2011).

The addition of alemtuzumab to a RIC regimen dramatically reduces the incidence of acute and chronic GVHD in patients with AML and MDS undergoing allogeneic transplantation, while TRM, relapse risk, OS and DFS are not affected (van Besien et al., 2009). In another study using alemtuzumab-based RIC alloSCT the 3-year non-relapse mortality (NRM) was $31 \%$, DFS was $41 \%$ and overall survival (OS) was $46 \%$. Comorbidity scoring and performance status have been suggested as strategies to guide dose adjustment and to identify fit 65- to 70-year-old patients who can tolerate myeloablative conditioning while those with comorbidities receive less intense regimens. HCT-CI was found to be an independent variable affecting 3-year NRM, DFS and OS, indicating that the HCT-CI provides an important means of stratifying patients with a high risk of inferior transplant outcomes (Lim et al., 2010a; Artz et al., 2006).

\subsubsection{AlloSCT for the elderly}

The median age of diagnosis for patients with MDS is 76 years of age with $86 \%$ of patients older than 60 years. The NCCN Practice Guidelines, as well as recent expert reviews, recommend alloSCT for patients with high-risk MDS without making any age restrictions (Greenberg, 2010). However, registry analysis show that few patients older than 65 years are actually undergoing this procedure.

There are no randomized controlled clinical trials evaluating the role of alloSCT for the treatment of elderly ( $>60$ years old) patients with intermediate- to high-risk MDS. The highest level of evidence is prospective cohort studies.

Two studies address the question of age and outcomes after transplantation.

Lim et al. recently published the results of their retrospective survey. Transplant outcomes of 1333 patients with MDS older than 50 years were reported to the European Group for Bone Marrow Transplant. The median age was 56 (range, 50 to 74) with $34 \%$ of patients being older than 60 years, $52 \%$ having advanced disease at the time of transplant and $62 \%$ receiving a RIC regimen. Overall survival for the whole group was $31 \%$ at 4 years, with $63 \%$ of patients dying of nonrelapse causes. The nonrelapse mortality rate was $36 \%$ at 4 years with no significant difference demonstrated in patients older or younger than 60 years. Patients receiving a myeloablative conditioning regimen had a higher risk of transplantrelated mortality than those receiving an RIC regimen (44\% v 32\%). Relapse rates were higher in patients receiving RIC regimens than those receiving myeloablative conditioning (41\% $v 33 \%)$. In their multivariate analysis, age was not a significant factor for clinical outcomes of relapse or survival. Significant factors associated with nonrelapse mortality included type of conditioning, advanced disease at transplantation, and donor type. The 4year overall survival estimate was not significantly different between those $<60$ years old and those $>60$ years old. However, relapse rate was increased in the $>60$-year-old cohort ( $32 \%$ vs $41 \%)$. Finally, relapse rate and survival were significantly affected by poor-risk cytogenetics (Lim, et al., 2010b). 
McClune et al. included 535 MDS patients and 545 AML patients in first complete remission registered with the Center for International Blood and Marrow Transplant Research from 1995 to 2005. All transplants were (RIC or nonmyeloablative (NMA) conditioning, in contrast to the prior study. Thirty-four percent of MDS patients and 36\% of AML patients were $>60$ years old. In both the MDS and AML cohorts, age did not significantly affect nonrelapse mortality, disease-free survival, or overall survival. Long-term disease control was seen in about one-third of MDS patients independent of age, supporting the curative potential of SCT for patients with MDS over the age of 60 (McClune et al., 2010).

Castagna et al. carried out a retrospective study of 63 patients $>60$ years with hematological malignancies and treated with RIC and alloSCT. Only the occurrence of aGVHD affected the TRM and OS. Acute GVHD is the main cause of TRM and more efforts should be made to reduce its incidence without sacrificing graft vs tumor effect (Castagna et al., 2010).

Umbilical cord blood (UCB) is feasible as an alternative donor source for RIC alloSCT among older patients with MDS who do not have suitable HLA-matched sibling donors (MSD). Majhail et al. compared outcomes of allo-SCT, using MSD or UCB among older patients (age over 55 years) with AML or MDS. All patients received a RIC regimen consisting of cyclophosphamid, fludarabine and 200 cGy TBI. Median age at alloSCT was 63 years for MSD and 61 years for UCB recipients. On multivariate analysis, donor source (MSD vs UCB) did not impact risks of OS, leukemia-free survival and relapse or treatmentrelated mortality (Majhail et al., 2011).

By means of the WPSS the impact of regular transfusion requirement (defined as requiring at least one transfusion every 8 weeks in a 4-month period) can be implicated into the risk stratification and those low-risk patients can be identified who can benefit of allo-SCT. Regular transfusion requirement is given the same regression weight as progressing to a higher cytogenetic risk group (Malcovati et al., 2007).

Based on the available evidence, transplantation for MDS in patients aged 60 or older is the only available curative therapy, but its benefit in terms of OS has not been demonstrated in randomized controlled trials. Careful patient selection may improve the results (Giralt et al., 2011; Ria et al,. 2009; Alatrash et al., 2011).

\subsubsection{The issue of the stem cell source and donor selection}

The patients with MDS who received peripheral blood stem cells (PBSC) had a faster engraftment and a lower relapse rate, resulting in improved DFS rates, than patients who received bone marrow stem cells (Guardiola et al., 2002). There is a shifting tendency towards to use PBSC rather than bone marrow stem cells.

Umbilical cord blood has increased access to hematopoietic cell transplantation (HCT) for patients without HLA-matched sibling donors (MSD).

A study was carried out through the Eurocord and European Group for Blood and Marrow Transplantation (EBMT) registries by Robin et al., aiming to evaluate the outcomes and risk factors in adult patients who underwent single or double unrelated cord blood transplantation (UCBT) for myelodysplastic syndrome (MDS) or secondary acute myeloblastic leukemia (sAML). A total of 180 adults with MDS ( $n=39)$ or sAML $(n=69)$ were analyzed. Median age was 43 (18-72) years. In all, 77 patients $(71 \%)$ received a single UCBT. Myeloablative conditioning regimen (MAC) was given to 57 (53\%) patients. A 2-year non-relapse mortality (NRM) was significantly higher after MAC (62 vs 34). A 2year DFS and overall survival (OS) were 30 and $34 \%$, respectively. In multivariate 
analysis, patients with high-risk disease (blasts $>5 \%$ and International Prognostic scoring system (IPSS) intermediate-2 or high in MDS) had significant poorer DFS. In spite of high NRM, these data indicate that UCBT is an acceptable alternative option to treat adults with high-risk MDS or sAML, without a suitable human leukocyte antigen (HLA)matched donor (Robin et al., 2011).

The rate of related versus unrelated donor is also changing. The percentage of older patients who are receiving unrelated donor transplants is increasing (Karanes et al., 2008).

A study compared allogeneic sibling-matched SCT data in MDS patients $\leq 60$ years old to clinical outcomes of age-matched non-treated comparable stage MDS patients. Markov decision-making statistical analysis indicated that higher risk IPSS patients $\leq 60$ years old should proceed to such human leucocyte antigen (HLA) identical sibling transplants at diagnosis, whereas for those lower risk MDS patients, delaying transplantation for several years and prior to disease progression would be beneficial (Cutler et al., 2004).

According to newer studies minor HLA disparity in unrelated compared to related donors could have a significant impact on transplant outcomes. To assess whether use of unrelated donors (URD) engenders more potent graft versus leukaemia effect in RIC alloSCT compared to matched related donors (MRD), a retrospective study has been performed Dana-Farber Cancer Institute on patients with different haematological malignancies including 66 MDS patients (Ho et al., 2010). Patients received uniformly fludarabine and intravenous busulfan conditioning, and GVHD prophylaxis with tacrolimus/minimethroxate (mini-MTX) or tacrolimus/sirolimus \pm mini-MTX. URD was associated with a lower risk of relapse ( $52 \%$ versus $65 \%)$.

\subsubsection{Reducing relapse rate}

The most important factors for TRM are age, co-morbidities, donor selection and intensity of the conditioning regimen. A careful donor selection and an appropriate choice of conditioning regimen will significantly reduce TRM.

On the other hand preferring RIC as preparative regimen, the incidence of relapse will be higher. So effords are made to reduce relapse rate. Either improving of the pretransplant remission status or by using post-transplant strategies, such as maintenance or consolidation therapies can play a role in reducing the risk of relapse (Kröger, 2008).

In addition to age, the cytogenetic risk score remained an independent prognostic factor for relapse. Lenalidomide has shown activity in terms of resolution of chromosomal abnormalities, especially in isolated 5q- but also in complex abnormalities involving 5q-. There are also some observations that MDS patients with poor cytogenetic abnormalities such as monosomy 7 may benefit from hypomethylating agents (Raj et al., 2007).

Besides improving pretransplant status of patients with MDS by inducing clinical and cytogenetic remission, further approaches to reduce the risk of relapse after alloSCT involve post-transplant modifications.

Donor lymphocyte infusion (DLI) can induce durable remission in relapsing patients with hematological malignancies after alloSCT. However, the experience of DLI in patients with MDS is limited. and the role of it is unclear. In Fred Hutchinson Cancer Research Center, Washington 16 patients treated with DLI for relapsed MDS after HCT between 1993 and 2004. CR with resolution of cytopenias and prior disease markers occurred in 3 of 14 patients who could be evaluated. Two patients survived without MDS for 68 and 65 months after DLI, respectively, but died with pneumonia. Grades II-IV acute GVHD and chronic 
GVHD occurred after DLI in $6(43 \%)$ and $5(36 \%)$ patients, respectively. All three responders developed grades III-IV acute GVHD and extensive chronic GVHD after DLI. This result refers that DLI can result in CR in some patients with relapsed MDS after transplant, but long-term survival is infrequent (Campregher et al., 2007). Azacitidine combined with DLI for relapsed patients may also result remission (Czibere et al., 2010).

Maintenance therapy with azacitidine is another option. Low dose azacitidine (at $\left.32 \mathrm{mg} / \mathrm{m}^{2}\right)$ given for 5 days is safe and can be administered after allogeneic transplant for at least 4 cycles to heavily pretreated AML/MDS patients. The trial also suggested that this treatment may prolong event-free and overall survival, and that more cycles may be associated with greater benefit (de Lima et al., 2010).

\subsubsection{Treatment of relapse}

Standard induction chemotherapy may be used for re-induction. The tolerability and potential of low dose azacitidine for treatment of relapsed MDS is supported by a Phase I trial (de Lima et al., 2010).

Immunotherapeutic strategies for example peptide vaccination targeting leukemiaassociated antigens, such as the Wilm's Tumor protein (WT1) (Keilholz et al., 2009) and whole cell leukemia vaccination with CD80 and IL-2 genetically modified leukemic blasts are currently the subjects of Phase I clinical trial (Ingram et al., 2009).

\subsubsection{The effect of iron oveload on the post-tranplantation survival}

Pre-transplantation transfusion history and serum ferritin have significant prognostic value in patients with myelodysplastic syndrome undergoing myeloablative allogeneic stem cell transplantation, inducing a significant increase of non-relapse mortality. An elevated serum ferritin $(>1000 \mu \mathrm{g} / \mathrm{L})$ has been associated with reduced OS and increased risk of infection following HSCT. Given that ferritin is an acute phase reactant, the elevated ferritin serum level alone does not considered to be a satisfactory marker of iron overload. Other biomarkers of body iron load should be taken into account to estimate the effect of iron overload on the post-transplantation survival (Pullarkat, 2010). These results indicate that transfusion history should be considered in transplantation decision-making in patients with myelodysplastic syndrome. Outcome was significantly worse in subjects receiving more than 20 red cell units.

Elevated pre-transplantation liver iron content estimated by magnetic resonance imaging (MRI) is significantly associated with inferior post-transplantation survival. There is a strong correlation between pre-transplantation serum ferritin level and liver iron content which was mostly dependent on prior transfusion history (Armand).

\subsection{New agents}

The past several years have brought exciting new treatments strategies for MDS. However, despite the huge progress, no curative therapy does exist exclusive of alloSCT nowadays. Furthermore, cure is not necessarily essential in the presence of drug therapy that can effectively control disease symptoms and prevent disease-related mortality (Tefferi, 2008; Rajkumar, 2008). Since the knowledge of molecular genetics in AML and MDS has expanded recently, targeted therapeutics should offer new possibilities for advancement (Bryan et al., 2010). 
The nucleoside analog clofarabine, and the alkylating agent cloretazine are now being tested. There are several clinical trials using new agents that act at a number of different levels. There are new agents with new therapeutic targets, for example tyrosine kinase inhibitors (FLT3 inhibitors), farnesyl-transferase inhibitors (Braun \& Fenaux, 2008), which are thought to target mutant ras activity, agents with c-jun modificating effect, MAP-kinase inhibitors, histone deacetylase inhibitors, which cause epigenetic alterations.

Using combination of drugs with different and new mechanism of action may also be a novel approach. Azacitidine in combination with histone deacetylase inhibitors might offer better efficacy by modulating the methylation and acetylation states of silenced genes. Silverman, 2009, Leuk res

Single-agent tipifarnib (a farnesyltransferase inhibitor) in high-risk MDS patients achieves responses comparable to those of standard epigenetic therapies, including hypomethylating agents, and for this reason, farnesyltransferase inhibitors deserve further in MDS. (Braun \& Fenaux, 2008; Grant, 2009).

\section{Recommendations for treating lower risk (IPSS low, intermediate-1 or WPSS very low, low and Intermediate) MDS patients}

Patients with del(5q) chromosomal abnormalities and symptomatic anaemia should receive lenalidomide.

Other patientswith symptomatic anaemia with EPO level $\leq 500 \mathrm{mU} / \mathrm{ml}$, should be treated with recombinant human EPO or darbepoetin with or without granulocyte-colony stimulatin factor (G-CSF). Non-responders should be considered for treatment with azacitidine, decitabine or lenalidomide.

Those anaemic patients with EPO levels $<500 \mathrm{mU} / \mathrm{ml}$ should be evaluated to determine whether they have a good probability of responding to immunosuppressive therapy. For those with low probability treatment with azacitidine, decitabine or lenalidomide should be recommended.

Non-responders and those with severe cytopenias participation in a clinical trial, or allo-SCT should be an option.

\section{Recommendations for treating higher risk (IPSS Intermediate-2, high-risk or WPSS high, very high) MDS patients}

Treatment recommendations for higher risk patients depend on whether they are candidate for intensive therapy. Decision should be made by considering the patient's age, comorbidities, physiosocial status and also the patient's preference and the availability of a suitable donor.

For eligible patients the first choice regarding the donor source has remained an HLAmatched sibling though results with HLA-matched unrelated donors have improved to a similar level.

Patients older than 55-60 years, particularly those with less than $10 \%$ marrow myeloblasts, would be conditioning with RIC. Patients with high blast count pretransplant debulking therapy is generally needed. Younger patients, regardless of marrow blast burden, will generally receive high dose conditioning.

For patients eligible for intensive therapy lacking a suitable donor using an intensive induction chemotherapy should be recommended. 
For higher risk patients who are not candidate for intensive therapy the use of azacitidine, decitabine or a participation in a clinical trial should be considered.

Good supportive care should be given to every MDS patients. This may be the only therapy for those with adverse clinical features or disease progression despite antitumor therapy.

\section{Conclusion}

Ten years ago, there was little to offer MDS patients other than transfusion support, but since then, the approach to treating patients with MDS has undergone a progress. New therapeutic options have added to the armamentarium of MDS treatments.

Historically, treatment goals have varied based on patient risk category, with modification of disease reserved for patients in the higher-risk population and response rates being a primary endpoint. In the light of recent data the treatment paradigm should be reevaluated to focus on prolonging time to leukemic transformation and extending survival while improving quality of life. Lenalidomide can modify disease activity, the methyltransferase inhibitors have the ability to prolong survival. These are shifting the focus away from response rates alone. Azacitidine has demonstrated a sustained impact on overall survival. In addition, data suggest that treatment with these therapeutics in patients with lower-risk disease may further extend survival by altering the biology of MDS. The new treatment paradigm should aim for prolonging leukemic-free transformation and extending survival while optimizing quality of life and maintaining hematologic and cytogenetic response.

The results of stem cell transplantation for MDS continue to improve together with the outlook of patients afflicted with myelodysplasia.

The incidence of MDS is increasing parallely with the increase of the average age of the population. That gives a particular importance to the development of MDS therapy has taken place in the last decade. In the close future some more possible progress are expected.

\section{References}

Advisory Committee of the International Bone Marrow Transplant Registry. 1989. Report from the International Bone Marrow Transplant Registry. Bone Marrow Transplant, $48,453-458$,

Alatrash G, de Lima M, Hamerschlak N, Pelosini M, Wang X, Xiao L, Kerbauy F, Chiattone A, Rondon G, Qazilbash MH, Giralt SA, de Padua Silva L, Hosing C, Kebriaei P, Zhang W, Nieto Y, Saliba RM, Champlin RE \& Andersson BS. 2011. Myeloablative Reduced-Toxicity i.v. Busulfan-Fludarabine and Allogeneic Hematopoietic Stem Cell Transplant for Patients with Acute Myeloid Leukemia or Myelodysplastic Syndrome in the Sixth through Eighth Decades of Life. Biol Blood Marrow Transplant, Febr. 18,

Alessandrino EP, Della Porta MG, Bacigalupo A, Van Lint MT, Falda M, Onida F, Bernardi M, Iori AP, Rambaldi A, Cerretti R, Marenco P, Pioltelli P, Malcovati L, Pascutto C, Oneto R, Fanin R \& Bosi A; Gruppo Italiano Trapianto di Midollo Osseo (GITMO). 2008. WHO classification and WPSS predict posttransplantation outcome in patients with myelodysplastic syndrome: a study from the Gruppo Italiano Trapianto di Midollo Osseo (GITMO). Blood, 112,3,895-902,

Armand P, Kim HT, Rhodes J, Sainvil MM, Cutler C, Ho VT, Koreth J, Alyea EP, Hearsey D, Neufeld EJ, Fleming MD, Steen H, Anderson D, Kwong RY, Soiffer RJ \& Antin JH. 
2011. Iron Overload in Patients with Acute Leukemia or MDS Undergoing Myeloablative Stem Cell Transplantation. Biol Blood Marrow Transplant,6,852-60,

Artz AS, Pollyea D \& Kocherginsky M. 2006. Performance status and comorbidity predict transplant related mortality after allogeneic hematopoietic cell transplantation. Biol Blood and Marrow Transplant,12,954-964,

Barrett J, Sloand E \& Young N. 2006. Determining which patients with myelodysplastic syndrome will respond to immunosuppressive treatment. Haematologica, 91,5,583-4,

Bartenstein M \& Deeg HJ. 2010. Hematopoietic stem cell transplantation for MDS. Hematol Oncol Clin North Am,24,2,407-22,

Barzi A \& Sekeres MA. 2010. Myelodysplastic syndromes: a practical approach to diagnosis and treatment. Cleve Clin J, Med, 77,1,37-44,

Bearman SI, Appelbaum FR, Buckner CD, Petersen FB, Fisher LD, Clift RA \& Thomas ED. 1988. Regimen-related toxicity in patients undergoing bone marrow transplantation. J Clin Oncol,6, 1562-1568,

Bello C, Yu D, Komrokji RS, Zhu W, Wetzstein GA, List AF \& Lancet JE. 2010. Outcomes after induction chemotherapy in patients with acute myeloid leukemia arising from myelodysplastic syndrome. Cancer, Nov. 8,

van Besien K, Kunavakkam R, Rondon G, De Lima M, Artz A, Oran B \& Giralt S. 2009. Fludarabine-melphalan conditioning for AML and MDS: alemtuzumab reduces acute and chronic GVHD without affecting long-term outcomes. Biol Blood Marrow Transplant,15,5,610-7,

Blum W. How much? How frequent? How long? 2010. A clinical guide to new therapies in myelodysplastic syndromes. Hematology Am Soc Hematol Educ Program,2010,314-21,

Boultwood J, Perry J \& Pellagatti A. 2010. Frequent mutation of the polycomb-associated gene ASXL1 in the myelodysplastic syndromes and in acute myeloid leukemia. Leukemia,524,5,1062-1065,

Braun T \& Fenaux P. 2008. Farnesyltransferase inhibitors and their potential role in therapy for myelodysplastic syndromes and acute myeloid leukaemia. Br J Haematol, 141,5,576-86,

Bryan J, Jabbour E, Prescott H, Garcia-Manero G, Issa JP \& Kantarjian H. 2010. Current and future management options for myelodysplastic syndromes. Drugs, 70,11,1381-94,

Campregher PV, Gooley T, Scott BL, Moravec C, Sandmaier B, Martin PJ, Deeg HJ, Warren EH \& Flowers ME. 2007. Results of donor lymphocyte infusions for relapsed myelodysplastic syndrome after hematopoietic cell transplantation. Bone Marrow Transplant, 40,10,965-71,

Castagna L, Fürst S, Marchetti N, El Cheikh J, Faucher C, Mohty M, Bouabdallah R, Vey N, Stoppa AM, Esterni B \& Blaise D. 2010. Retrospective analysis of common scoring systems and outcome in patients older than 60 years treated with reduced-intensity conditioning regimen and alloSCT. Bone Marrow Transplant, Oct 4,

Chamuleau ME, Westers TM, van Dreunen L, Groenland J, Zevenbergen A, Eeltink CM, Ossenkoppele GJ \& van de Loosdrecht AA. 2009. Immune mediated autologous cytotoxicity against hematopoietic precursor cells in patients with myelodysplastic syndrome. Haematologica, 94,4,496-506,

Cutler CS, Lee SJ \& Greenberg P. 2004. A decision analysis of allogeneic bone marrow transplantation for the myelodysplastic syndromes: delayed transplantation for low-risk myelodysplasia is associated with improved outcome. Blood,104,579-585, 
Cutler C. 2010. Patient selection for transplantation in the myelodysplastic syndromes. Hematol Oncol Clin North Am,24,2,469-76,

Cutler C. 2010. Allogeneic hematopoietic stem-cell transplantation for myelodysplastic syndrome. Hematology Am Soc Hematol Educ Program,2010,325-9,

Czibere A, Bruns I, Kröger N, Platzbecker U, Lind J, Zohren F, Fenk R, Germing U, Schröder T, Gräf T, Haas R \& Kobbe G. 2010. 5-Azacytidine for the treatment of patients with acute myeloid leukemia or myelodysplastic syndrome who relapse after alloSCT: a retrospective analysis. Bone Marrow Transplant,45,5,872-6,

Deeg HJ, Jiang PY, Holmberg LA, Scott B, Petersdorf EW \& Appelbaum FR. 2004. Hematologic responses of patients with MDS to antithymocyte globulin plus etanercept correlate with improved flow scores of marrow cells. Leuk Res, 28,117780,

Ebert BL, Pretz J \& Bosco J. 2008. Identification of RPS14 as a 5q- syndrome gene by RNA interference screen. Nature,451,335-339,

Edlin R, Connock M, Tubeuf S, Round J, Fry-Smith A, Hyde C \& Greenheld W. 2010. Azacitidine for the treatment of myelodysplastic syndrome, chronic myelomonocytic leukaemia and acute myeloid leukaemia. Health Technol Assess,14 Suppl 1,69-74,

Gale RP \& Champlin RE. 1984. How does bone-marrow transplantation cure leukaemia? Lancet,2, 28-30,

Garcia JS, Jain N \& Godley LA. 2010. An update on the safety and efficacy of decitabine in the treatment of myelodysplastic syndromes. Onco Targets Ther, 3,1-13,

Garcia-Manero G. 2010. Prognosis of myelodysplastic syndromes. Hematology Am Soc Hematol Educ Program,2010,330-7,

Gergis U \& Wissa U. 2010. High-risk myelodysplastic syndromes: chemotherapy, transplantation, and beyond. Curr Hematol Malig Rep, 5,1,1-8,

Giralt SA, Horowitz M, Weisdorf D \& Cutler C. 2011. Review of stem-cell transplantation for myelodysplastic syndromes in older patients in the context of the Decision Memo for Allogeneic Hematopoietic Stem Cell Transplantation for Myelodysplastic Syndrome emanating from the Centers for Medicare and Medicaid Services. J Clin Oncol,29,5,566-72,

Giralt S, Khouri I \& Champlin R. 1999. Non-myeloablative "mini transplants." Cancer Treat Res, 101, 97-108,

Giralt S, Thall P \& Khouri I. 2001. Purine analogcontaining preparative regimens: reducedintensity conditioning for patients with hematologic malignancies undergoing allogeneic progenitor cell transplantation. Blood,97, 631-637,

Goldberg SL, Chen E, Corral M, Guo A, Mody-Patel N, Pecora AL \& Laouri M. 2010. Incidence and clinical complications of myelodysplastic syndromes among United States Medicare beneficiaries. J Clin Oncol,28,17,2847-52,

Greenberg PL. 1998. Risk factors and their relationship to prognosis in myelodysplastic syndromes. Leuk Res, 22 Suppl 1,S3-6,

Greenberg PL, Sun Z, Miller KB, Bennett JM, Tallman MS, Dewald G, Paietta E, van der Jagt R, Houston J, Thomas ML, Cella D \& Rowe JM. 2009. Treatment of myelodysplastic syndrome patients with erythropoietin with or without granulocyte colonystimulating factor: results of a prospective randomized phase 3 trial by the Eastern Cooperative Oncology Group (E1996). Blood,114,12,2393-400, 
Greenberg PL. 2010. Current therapeutic approaches for patients with myelodysplastic syndromes. Br J Haematol,150,2,131-43,

Grant S. 2009. New agents for AML and MDS. Best Pract Res Clin Haematol,22,4,501-7,

Guardiola P, Runde V \& Bacigalupo A. 2002. Subcommittee for Myelodysplastic Syndromes of the Chronic Leukaemia Working Group of the European Blood and Marrow Transplantation Group. Retrospective comparison of bone marrow and granulocyte colony-stimulating factor-mobilized peripheral blood progenitor cells for allogeneic stem cell transplantation using HLA identical sibling donors in myelodysplastic syndromes. Blood,99,4370-4378,

Graubert T. 2010. Therapy-related myelodysplastic syndrome: models and genetics. Biol Blood Marrow Transplant, 16,1, suppl,S45-S47,

Grövdal M, Karimi M, Khan R, Aggerholm A, Antunovic P, Astermark J, Bernell P, Engström LM, Kjeldsen L, Linder O, Nilsson L, Olsson A, Holm MS, Tangen JM, Wallvik J, Oberg G, Hokland P, Jacobsen SE, Porwit A \& Hellström-Lindberg E. 2010. Maintenance treatment with azacytidine for patients with high-risk myelodysplastic syndromes (MDS) or acute myeloid leukaemia following MDS in complete remission after induction chemotherapy. Br J Haematol,150,3,293-302,

Hellström-Lindberg E. 2003. Approach to anemia associated with myelodysplastic syndromes. Curr Hematol Rep,2,2,122-9,

Ho VT, Kim HT, Aldridge J, Liney D, Kao G, Armand P, Koreth J, Cutler C, Ritz J, Antin JH, Soiffer RJ \& Alyea EP. 2010. Use of Matched Unrelated Donors Compared with Matched Related Donors Is Associated with Lower Relapse and Superior Progression-Free Survival after Reduced-Intensity Conditioning Hematopoietic Stem Cell Transplantation. Biol Blood Marrow Transplant, 12,702,

Horwitz ME. 2011. Reduced intensity versus myeloablative allogeneic stem cell transplantation for the treatment of acute myeloid leukemia, myelodysplastic syndrome and acute lymphoid leukemia. Curr Opin Oncol,23,2,:197-202,

Ingram W, Chan L, Guven H, Darling D, Kordasti S, Hardwick N, Barber L, Mufti GJ \& Farzaneh F. 2009. Human CD80/IL2 lentivirus-transduced acute myeloid leukaemia (AML) cells promote natural killer (NK) cell activation and cytolytic activity: implications for a phase I clinical study. Br J Haematol,145,6,749-60,

Jädersten M, Malcovati L, Dybedal I, Della Porta MG, Invernizzi R, Montgomery SM, Pascutto C, Porwit A, Cazzola M \& Hellström-Lindberg E. 2008. Erythropoietin and granulocyte-colony stimulating factor treatment associated with improved survival in myelodysplastic syndrome. J Clin Oncol,26,21,3607-13,

Jankowska AM, Szpurka H \& Tiu RV. 2009. Loss of heterozygosity 4q24 and TET2 mutations associated with myelodysplastic/myeloproliferative neoplasms. Blood,113,6403-6410,

Kantarjian H, Issa JP, Rosenfeld CS, Bennett JM, Albitar M \& DiPersio J. 2006. Decitabine improves patient outcomes in myelodysplastic syndromes: results of a phase III randomized study. Cancer,106,1794-1803,

Kantarjian H, Oki Y, Garcia-Manero G, Huang X, O’Brien S \& Cortes J. 2007. Results of a randomized study of 3 schedules of low-dose decitabine in higher-risk myelodysplastic syndrome and chronic myelomonocytic leukemia. Blood,109,52-57,

Karanes C, Nelson GO, Chitphakdithai P, Agura E, Ballen KK, Bolan CD, Porter DL, Uberti JP, King RJ \& Confer DL. 2008. Twenty years of unrelated donor hematopoietic cell 
transplantation for adult recipients facilitated by the National Marrow Donor Program. Biol Blood Marrow Transplant,14,9 Suppl,8-15,

Keilholz U, Letsch A, Busse A, Asemissen AM, Bauer S, Blau IW, Hofmann WK, Uharek L, Thiel E \& Scheibenbogen C. 2009. A clinical and immunologic phase 2 trial of Wilms tumor gene product 1 (WT1) peptide vaccination in patients with AML and MDS. Blood,113,26,6541-8,

Kiladjian JJ, Visentin G, Viey E, Chevret S, Eclache V, Stirnemann J, Bourhis JH, Chouaib S, Fenaux P \& Caignard A. 2008. Activation of cytotoxic T-cell receptor gammadelta T lymphocytes in response to specific stimulation in myelodysplastic syndromes. Haematologica,93,3,381-9,

Kindwall-Keller T \& Isola LM. 2009. The evolution of hematopoietic SCT in myelodysplastic syndrome. Bone Marrow Transplant, 43,8,597-609,

Komrokji RS \& List AF. 2010. Lenalidomide for treatment of myelodysplastic syndromes: current status and future directions. Hematol Oncol Clin North Am, 24,2,377-88,

Kröger N. 2008. Epigenetic modulation and other options to improve outcome of stem cell transplantation in MDS. Hematology Am Soc Hematol Educ Program,60-7,

Kurtin SE \&, Demakos EP. 2010. An update on the treatment of myelodysplastic syndromes. Clin J Oncol Nurs,14,3,E29-44,

Laport GG, Sandmaier BM, Storer BE, Scott BL, Stuart MJ, Lange T, Maris MB, Agura ED, Chauncey TR, Wong RM, Forman SJ, Petersen FB, Wade JC, Epner E, Bruno B, Bethge WA, Curtin PT, Maloney DG, Blume KG \& Storb RF. 2008. Reducedintensity conditioning followed by allogeneic hematopoietic cell transplantation for adult patients with myelodysplastic syndrome and myeloproliferative disorders. Biol Blood Marrow Transplant, 14,2,246-55.

Lee JH, Choi J, Kwon KA, Lee S, Oh SY, Kwon HC, Kim HJ, Han JY \& Kim SH. 2010. Fludarabine-based myeloablative regimen as pretransplant conditioning therapy in adult acute leukemia/myelodysplastic syndrome: comparison with oral or intravenous busulfan with cyclophosphamide. Korean J Hematol, 45,2,102-8,

Lim Z, Brand R \& Martino R. 2010. Allogeneic hematopoietic stem-cell transplantation for patients 50 years or older with myelodysplastic syndromes or secondary acute myeloid leukemia. J Clin Oncol,28,405-411,

de Lima M, Giralt S, Thall PF, de Padua Silva L, Jones RB, Komanduri K, Braun TM, Nguyen HQ, Champlin R \& Garcia-Manero G. 2010. Maintenance therapy with low-dose azacitidine after allogeneic hematopoietic stem cell transplantation for recurrent acute myelogenous leukemia or myelodysplastic syndrome: a dose and schedule finding study. Cancer, 116,23,5420-31,

de Lima M, Anagnostopoulos A, Munsell M, Shahjahan M, Ueno N, Ippoliti C, Andersson BS, Gajewski J, Couriel D, Cortes J, Donato M, Neumann J, Champlin R \& Giralt S. 2004. Nonablative versus reduced-intensity conditioning regimens in the treatment of acute myeloid leukemia and high-risk myelodysplastic syndrome: dose is relevant for long-term disease control after allogeneic hematopoietic stem cell transplantation. Blood,104,3,865-72,

List A, Dewald G \& Bennett J. 2006. Lenalidomide in the myelodysplastic syndrome with chromosome $5 q$ deletion. N Engl J Med,355,1456-1465,

List AF. 2010. Iron overload in myelodysplastic syndromes: diagnosis and management. Cancer Control, 17 Suppl,2-8, 
Litzow MR, Tarima S, Pérez WS, Bolwell BJ, Cairo MS, Camitta BM, Cutler CS, de Lima M, Dipersio JF, Gale RP, Keating A, Lazarus HM, Luger S, Marks DI, Maziarz RT, McCarthy PL, Pasquini MC, Phillips GL, Rizzo JD, Sierra J, Tallman MS \& Weisdorf DJ 2010. Allogeneic transplantation for therapy-related myelodysplastic syndrome and acute myeloid leukemia. Blood,115,9,1850-7,

Luger SM, Ringdén O, Zhang MJ, Pérez WS, Bishop MR, Bornhauser M, Bredeson CN, Cairo MS, Copelan EA, Gale RP, Giralt SA, Gulbas Z, Gupta V, Hale GA, Lazarus HM, Lewis VA, Lill MC, McCarthy PL, Weisdorf DJ \& Pulsipher MA. 2011. Similar outcomes using myeloablative vs reduced-intensity allogeneic transplant preparative regimens for AML or MDS. Bone Marrow Transplant, Mar 28.

Ma, X., Does, M., Raza, A., \& Mayne, S.T. 2007. Myelodysplastic syndromes: Incidence and survival in the United States. Cancer, 109, 1536-1542,

Majhail NS, Brunstein CG, Shanley R, Sandhu K, McClune B, Oran B, Warlick ED, Wagner JE \& Weisdorf DJ. 2011. Reduced-intensity hematopoietic cell transplantation in older patients with AML/MDS: umbilical cord blood is a feasible option for patients without HLA-matched sibling donors. Bone Marrow Transplant, 14,3,282-9,

Malcovati L, Della Porta MG \& Pascutto C. 2005. Prognostic factors and life expectancy in myelodysplastic syndromes classified according to WHO criteria: a basis for clinical decision making. J Clin Oncol, 23,30,7594-7603,

Malcovati L, Germing U, Kuendgen A, Della Porta MG, Pascutto C, Invernizzi R, Giagounidis A, Hildebrandt B, Bernasconi P, Knipp S, Strupp C, Lazzarino M, Aul C \& Cazzola M. 2007. Time-dependent prognostic scoring system for predicting survival and leukemic evolution in myelodysplastic syndromes. J Clin Oncol,25,23,3503-10,

Malcovati L \& Nimer SD. 2008. Myelodysplastic syndromes: diagnosis and staging. Cancer Control, 15 Suppl,4-13,

McClune BL, Weisdorf DJ \& Pedersen TL. 2010. Effect of age on outcome of reducedintensity hematopoietic cell transplantation for older patients with acute myeloid leukemia in first complete remission or with myelodysplastic syndrome. J Clin Oncol,28,1878-1887,

McCormack SE \& Warlick ED. 2010. Epigenetic approaches in the treatment of myelodysplastic syndromes: clinical utility of azacitidine. Onco Targets Ther, 3,15765 ,

Meletis J \& Terpos E. 2009. Transplantation strategies for the management of patients with myelodysplastic syndromes. J BUON,14,4,551-64,

Mufti GJ \& Chen TL. 2008. Changing the treatment paradigm in myelodysplastic syndromes. Cancer Control, 15 Suppl,14-28,

National Comprehensive Cancer Network (2010) The NCCN 2.2010 Myelodysplastic Syndromes Clinical Practice Guidelines in Oncology (National Comprehensive Cancer Network, Fort Washington, PA).

Park S , Kelaidi C, Sapena R, Vassilieff D, Beyne-Rauzy O, Coiteux V, Vey N, Ravoet C, Cheze S, Rose C, Legros L, Stamatoullas A, Escoffre-Barbe M, Guerci A, Chaury MP, Fenaux P \& Dreyfus F. 2010. Early introduction of ESA in low risk MDS patients may delay the need for RBC transfusion: a retrospective analysis on 112 patients. Leuk Res, 34,11,1430-6, 
Passweg JR, Giagounidis AA, Simcock M, Aul C, Dobbelstein C, Stadler M, Ossenkoppele G, Hofmann WK, Schilling K, Tichelli A \& Ganser A. 2011. Immunosuppressive therapy for patients with myelodysplastic syndrome: a prospective randomized multicenter phase III trial comparing antithymocyte globulin plus cyclosporine with best supportive care--SAKK 33/99. J Clin Oncol,29,3,303-9,

Pullarkat V. 2010. Iron overload in patients undergoing hematopoietic stem cell transplantation. Adv Hematol, 2010. pii: 345756,

Pullarkat V. 2009. Objectives of iron chelation therapy in myelodysplastic syndromes: more than meets the eye? Blood,114,26,5251-5,

Raj K, John A \& Ho A. 2007. CDKN2B methylation status and isolated chromosome 7 abnormalities predict responses to treatment with 5-azacytidine. Leukemia,;21,19371944 ,

Rajkumar SV. 2008. Treatment of myeloma: cure vs control. Mayo Clin Proc,83,1142-1145,

Ria R, Moschetta M, Reale A, Mangialardi G, Castrovilli A, Vacca A \& Dammacco F. 2009. Managing myelodysplastic symptoms in elderly patients. Clin Interv Aging, 4,41323,

Rizzo JD, Brouwers M, Hurley P, Seidenfeld J, Arcasoy MO, Spivak JL, Bennett CL, Bohlius J, Evanchuk D, Goode MJ, Jakubowski AA, Regan DH \& Somerfield MR. 2010. American Society of Hematology and the American Society of Clinical Oncology Practice Guideline Update Committee, American Society of Hematology/American Society of Clinical Oncology clinical practice guideline update on the use of epoetin and darbepoetin in adult patients with cancer. Blood,116,20,4045-59,

Robin M, Sanz GF, Ionescu I, Rio B, Sirvent A, Renaud M, Carreras E, Milpied N, Mohty M, Beguin Y, Bordigoni P, de Witte T, Picardi A, Purtill D, Gluckman E, Kroger N \& Rocha V. 2011. Unrelated cord blood transplantation in adults with myelodysplasia or secondary acute myeloblastic leukemia: a survey on behalf of Eurocord and CLWP of EBMT. Leukemia,25,1,75-81,

Sanada M, Suzuki T \& Shih LY. 2009. Gain-of-function of mutated C-CBL tumour suppressor in myeloid neoplasms. Nature,460,904-908,

San Miguel Amigo L, Franco Osorio R, Mercadal Vilchez S \& Martínez-Francés A. 2011. Azacitidine adverse effects in patients with myelodysplastic syndromes. Adv Ther, 28 Suppl 4,6-11,

Scott BL \& Estey E 2008. Management of myelodysplastic syndromes: 2008 update. Oncology (Williston Park), 22,12,1344-52,

Sekeres MA, Maciejewski JP, Giagounidis AA, Wride K, Knight R \& Raza A. 2008. Relationship of treatment-related cytopenias and response to lenalidomide in patients with lower-risk myelodysplastic syndromes. J Clin Oncol,26, 5943-5949,

Sekeres MA. 2009. Treatment of MDS: something old, something new, something borrowed.... Hematology Am Soc Hematol Educ Program,656-63,

Sekeres MA. 2011a. Epidemiology, natural history, and practice patterns of patients with myelodysplastic syndromes in 2010. J Natl Compr Canc Netw,9,1,57-63,

Sekeres MA, List AF, Paulic K, Afable M, Englehaupt R \& Maciejewski JP. 2011b. Demonstration of additional benefit in adding lenalidomide to azacitidine in patients with higher-risk myelodysplastic syndromes. Am J Hematol,86,1,102-3. 
Silverman LR. 2009. Hypomethylating agents in myelodysplastic syndromes changing the inevitable: the value of azacitidine as maintenance therapy, effects on transfusion and combination with other agents. Leuk Res,33 Suppl 2,S18-21,

Sloand EM, Olnes MJ, Shenoy A, Weinstein B, Boss C, Loeliger K, Wu CO, More K, Barrett AJ, Scheinberg P \& Young NS. 2010. Alemtuzumab treatment of intermediate-1 myelodysplasia patients is associated with sustained improvement in blood counts and cytogenetic remissions. J Clin Oncol,28,35,5166-73,

Sloand EM, Wu CO, Greenberg P, Young N \& Barrett J. 2008. Factors affecting response and survival in patients with myelodysplasia treated with immunosuppressive therapy. J Clin Oncol,26,15,2505-11,

Sloand EM, Olnes MJ, Shenoy A, Weinstein B, Boss C, Loeliger K, Wu CO, More K, Barrett AJ, Scheinberg P \& Young NS. 2010. Alemtuzumab treatment of intermediate-1 myelodysplasia patients is associated with sustained improvement in blood counts and cytogenetic remissions. J Clin Oncol,28,35,5166-73,

Sorror ML, Maris MB \& Storb R. 2005. Hematopoietic cell transplantation (HCT)-specific comorbidity index: a new tool for risk assessment before allogeneic HCT. Blood,106,2912-2919,

Steensma DP. 2009. Myelodysplasia paranoia: iron as the new radon. Leuk Res,33,9,1158-63,

Steensma DP, Baer MR, Slack JL, Buckstein R, Godley LA \& Garcia-Manero G. 2009. Multicenter study of decitabine administered daily for 5 days every 4 weeks to adults with myelodysplastic syndromes: the alternative dosing for outpatient treatment (ADOPT) trial. J Clin Oncol,27,3842-3848,

Tefferi A. 2008. Is "cure" essential in the treatment of cancer [letter]? Mayo Clin Proc,83,14131414 ,

Tefferi A. 2010. Myelodysplastic syndromes--many new drugs, little therapeutic progress. Mayo Clin Proc, 85,11,1042-5,

Virchis A, Koh M, Rankin P, Mehta A, Potter M, Hoffbrand AV \& Prentice HG. 2004. Fludarabine, cytosine arabinoside, granulocyte-colony stimulating factor with or without idarubicin in the treatment of high risk acute leukaemia or myelodysplastic syndromes. Br J Haematol, 124,1,6-32,

Vigil CE, Martin-Santos T \& Garcia-Manero G. 2010. Safety and efficacy of azacitidine in myelodysplastic syndromes. Drug Des Devel Ther, 4,221-9,

Warlick ED. 2010. Optimizing stem cell transplantation in myelodysplastic syndromes: unresolved questions. Curr Opin Oncol,22,2,150-4,

Wei S, Chen X, Rocha K, Epling-Burnette PK, Djeu JY, Liu Q, Byrd J, Sokol L, Lawrence N, Pireddu R, Dewald G, Williams A, Maciejewski J \& List A. 2009. A critical role for phosphatase haplodeficiency in the selective suppression of deletion $5 \mathrm{q}$ MDS by lenalidomide. Proc Natl Acad Sci U S A,106(31),12974-9,

Wijermans P, Suciu S, Baila L, Platzbecker U, Giagounidis A \& Selleslag D. 2009. Low dose decitabine versus best supportive care in elderly patients with intermediate or high risk MDS not eligible for intensive chemotherapy: final results of the randomized phase III study (06011) of the EORTC Leukemia and German MDS Study Groups. [abstract 226]. Blood, 114,22,

de Witte T, Brand R, van Biezen A, Delforge M, Biersack H, Or R, Meloni G, Bandini B, Sierra J, Kroger N, Gratwohl A \& Niederwieser D. 2006. MDS subcommittee of the EBMT Chronic Leukemia Working Party. The role of stem cell source in autologous 
hematopoietic stem cell transplantation for patients with myelodysplastic syndromes. Haematologica, 91,6,750-6,

de Witte T, Suciu S, Brand R, Muus P \& Kröger N. 2007. Autologous stem cell transplantation in myelodysplastic syndromes. Semin Hematol,44,4,274-7,

de Witte T, Hagemeijer A, Suciu S, Belhabri A, Delforge M, Kobbe G, Selleslag D, Schouten HC, Ferrant A, Biersack H, Amadori S, Muus P, Jansen JH, Hellström-Lindberg E, Kovacsovics T, Wijermans P, Ossenkoppele G, Gratwohl A, Marie JP \& Willemze R. 2010. Value of allogeneic versus autologous stem cell transplantation and chemotherapy in patients with myelodysplastic syndromes and secondary acute myeloid leukemia. Final results of a prospective randomized European Intergroup Trial. Haematologica,95,10,1754-61,

Ximeri M, Galanopoulos A, Klaus M, Parcharidou A, Giannikou K, Psyllaki M, Symeonidis A, Pappa V, Kartasis Z, Liapi D, Hatzimichael E, Kokoris S, Korkolopoulou P, Sambani C, Pontikoglou C \& Papadaki HA. 2010. Hellenic MDS Study Group, Effect of lenalidomide therapy on hematopoiesis of patients with myelodysplastic syndrome associated with chromosome $5 q$ deletion. Haematologica, 95,3,406-14,

Yang X, Lay F, Han H \& Jones PA. 2010. Targeting DNA methylation for epigenetic therapy. Trends Pharmacol Sci, 31,11,536-46,

Zipperer E , Pelz D, Nachtkamp K, Kuendgen A, Gattermann N, Haas R \& Germing U. 2009. The hematopoietic stem cell transplantation comorbidity index is of prognostic relevance for patients with myelodysplastic syndrome. Haematologica, 94,5,729-32,

Zy Ingram W, Brand R, Ho A, Kenyon M, Devereux S, Marsh J, Mufti GJ \& Pagliuca. 2010. A Impact of pretransplant comorbidities on alemtuzumab-based reduced-intensity conditioning allogeneic hematopoietic SCT for patients with high-risk myelodysplastic syndrome and AML. Bone Marrow Transplant,45,4,633-9 


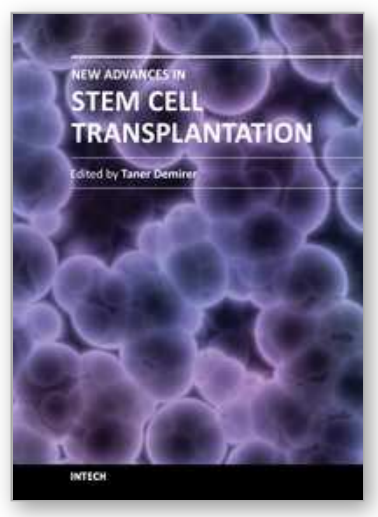

\author{
New Advances in Stem Cell Transplantation \\ Edited by Prof. Taner Demirer
}

ISBN 978-953-51-0013-3

Hard cover, 582 pages

Publisher InTech

Published online 24, February, 2012

Published in print edition February, 2012

This book documents the increased number of stem cell-related research, clinical applications, and views for the future. The book covers a wide range of issues in cell-based therapy and regenerative medicine, and includes clinical and preclinical chapters from the respected authors involved with stem cell studies and research from around the world. It complements and extends the basics of stem cell physiology, hematopoietic stem cells, issues related to clinical problems, tissue typing, cryopreservation, dendritic cells, mesenchymal cells, neuroscience, endovascular cells and other tissues. In addition, tissue engineering that employs novel methods with stem cells is explored. Clearly, the continued use of biomedical engineering will depend heavily on stem cells, and this book is well positioned to provide comprehensive coverage of these developments.

\title{
How to reference
}

In order to correctly reference this scholarly work, feel free to copy and paste the following:

Klara Gadó and Gyula Domján (2012). Treatment Options in Myelodysplastic Syndromes, New Advances in Stem Cell Transplantation, Prof. Taner Demirer (Ed.), ISBN: 978-953-51-0013-3, InTech, Available from: http://www.intechopen.com/books/new-advances-in-stem-cell-transplantation/treatment-options-inmyelodysplastic-syndromes

\section{INTECH}

open science | open minds

\section{InTech Europe}

University Campus STeP Ri Slavka Krautzeka 83/A

51000 Rijeka, Croatia Phone: +385 (51) 770447

Fax: +385 (51) 686166

www.intechopen.com

\section{InTech China}

Unit 405, Office Block, Hotel Equatorial Shanghai

No.65, Yan An Road (West), Shanghai, 200040, China

中国上海市延安西路65号上海国际贵都大饭店办公楼 405 单元

Phone: +86-21-62489820

Fax: +86-21-62489821 
(C) 2012 The Author(s). Licensee IntechOpen. This is an open access article distributed under the terms of the Creative Commons Attribution 3.0 License, which permits unrestricted use, distribution, and reproduction in any medium, provided the original work is properly cited. 